\title{
ACCURACY OF $\mathrm{CO}_{2}$ SENSORS IN COMMERCIAL BUILDINGS: A PILOT STUDY
}

\author{
William J. Fisk, David Faulkner, and Douglas P. Sullivan \\ Environmental Energy Technologies Division \\ Indoor Environment Department \\ 1 Cyclotron Road, 90R3058 \\ Lawrence Berkeley National Laboratory \\ Berkeley, CA 94720
}

October 2006

This work was supported by the Assistant Secretary for Energy Efficiency and Renewable Energy, Building Technologies Program of the U.S. Department of Energy under contract DEAC02-05CH11231. 


\title{
ACCURACY OF $\mathrm{CO}_{2}$ SENSORS IN COMMERCIAL BUILDINGS: A PILOT STUDY
}

\author{
William J. Fisk, David Faulkner, and Douglas P. Sullivan \\ Indoor Environment Department \\ 1 Cyclotron Road, 90R3058 \\ Lawrence Berkeley National Laboratory \\ Berkeley, Ca
}

October 2006

\begin{abstract}
Carbon dioxide $\left(\mathrm{CO}_{2}\right)$ sensors are often deployed in commercial buildings to obtain $\mathrm{CO}_{2}$ data that are used to automatically modulate rates of outdoor air supply. The goal is to keep ventilation rates at or above code requirements, but to also to save energy by avoiding overventilation relative to code requirements. However, there have been many anecdotal reports of poor $\mathrm{CO}_{2}$ sensor performance in actual commercial building applications. This study evaluated the accuracy of $44 \mathrm{CO}_{2}$ sensors located in nine commercial buildings to determine if $\mathrm{CO}_{2}$ sensor performance, in practice, is generally acceptable or problematic. $\mathrm{CO}_{2}$ measurement errors varied widely and were sometimes hundreds of parts per million. Despite its small size, this study provides a strong indication that the accuracy of $\mathrm{CO}_{2}$ sensors used in commercial buildings is frequently less than is needed to measure peak indoor-outdoor $\mathrm{CO}_{2}$ concentration differences with less than a $20 \%$ error. Thus, we conclude that there is a need for more accurate $\mathrm{CO}_{2}$ sensors and/or better sensor maintenance or calibration procedures.
\end{abstract}




\section{INTRODUCTION}

People produce and exhale carbon dioxide $\left(\mathrm{CO}_{2}\right)$ as a consequence of their normal metabolic processes; thus, the concentrations of $\mathrm{CO}_{2}$ inside occupied buildings are higher than the concentrations of $\mathrm{CO}_{2}$ in the outdoor air. The magnitude of the indoor-outdoor concentration difference decreases as the building's ventilation rate per person increases. If the building has a nearly constant occupancy for several hours and the ventilation rate is nearly constant, the ventilation rate per person can be estimated with fair accuracy from the maximum steady state difference between indoor and outdoor $\mathrm{CO}_{2}$ concentrations (ASTM 1998). For example, under steady conditions, if the indoor $\mathrm{CO}_{2}$ concentration in an office work environment is 650 parts per million above the outdoor concentration, the ventilation rate is approximately $15 \mathrm{cfm}$ per person. In many real buildings, occupancy and ventilation rates are not stable for sufficient periods to enable an accurate determination of ventilation rate from $\mathrm{CO}_{2}$ data; however, $\mathrm{CO}_{2}$ concentrations remain an approximate and easily measured surrogate for ventilation rate. The difference between the indoor and outdoor $\mathrm{CO}_{2}$ concentration is also an indicator of the indoor concentrations of other occupant- generated bioeffluents, such as body odors.

Epidemiological research has found that indoor $\mathrm{CO}_{2}$ concentrations are useful in predicting human health and performance. Many studies have found that occupants of office buildings with a higher difference between indoor and outdoor $\mathrm{CO}_{2}$ concentration have, on average, increased sick building syndrome health symptoms (Seppanen et al. 1999). In a study within a jail, higher $\mathrm{CO}_{2}$ concentrations were associated with increased respiratory disease (Hoge et al 1994) and higher $\mathrm{CO}_{2}$ concentrations in schools have been associated with increased student absence (Shendell et. al 2004). Shaughnessy et al (2006) found poorer student performance on standardized academic performance tests correlated with increased $\mathrm{CO}_{2}$ in classrooms and Wargocki and Wyon (1996) found that students performed various school-work tasks less rapidly or less accurately when the classroom $\mathrm{CO}_{2}$ concentration was higher.

In a control strategy called demand controlled ventilation, $\mathrm{CO}_{2}$ sensors, sometimes called $\mathrm{CO}_{2}$ transmitters, are often used in commercial buildings to obtain $\mathrm{CO}_{2}$ data that are used to automatically modulate rates of outdoor air supply. The goal is to keep ventilation rates at or above code requirements but to also adjust the outside air supply rate with changes in occupancy in order to save energy by avoiding over-ventilation relative to code requirements. Some buildings use $\mathrm{CO}_{2}$ sensors just to provide feedback about ventilation rates to the building operator, without automatic modulation of ventilation rates based on the measured $\mathrm{CO}_{2}$ concentrations.

Reviews of the research literature on demand controlled ventilation (Apte 2006, Emmerich and Persily 2001, Fisk and de Almeida 1998) indicates a significant potential for energy savings, particularly in buildings or spaces with a high and variable occupancy. However, there have been many anecdotal reports of poor $\mathrm{CO}_{2}$ sensor performance in actual applications of demand controlled ventilation. In a presentation by the Iowa Energy Center ${ }^{1}$ on an intercomparison of three $\mathrm{CO}_{2}$ sensors over time, the measured concentrations of different sensors varied by as much as $265 \mathrm{ppm}$.

\footnotetext{
${ }^{1}$ John House, Iowa Energy Center, jhouse@nrcan.gc.ca
} 
Based on the prior discussion, there is a good justification for monitoring indoor $\mathrm{CO}_{2}$ concentrations and using these concentrations to modulate rates of outdoor air supply. However, this strategy will only be effective if $\mathrm{CO}_{2}$ sensors have a reasonable accuracy in practice. The objective of this study was; therefore, to gain some initial data on the performance of $\mathrm{CO}_{2}$ sensors in field settings to determine if $\mathrm{CO}_{2}$ sensor performance, in practice, is generally acceptable or problematic.

\section{METHODS}

Two different protocols were employed to assess the accuracy of $44 \mathrm{CO}_{2}$ sensors located in 9 buildings within California. When possible, we used bags of $\mathrm{CO}_{2}$ calibration gases to evaluate sensor performance at five $\mathrm{CO}_{2}$ concentrations from 236 to 1180 parts per million (ppm). Based on the specifications of the calibration gas supplier and the protocols employed, the calibration gas concentrations were known within about $7 \%$ at the lowest concentration and within $2 \%$ at the highest concentration. In the multi-point calibration checks, the $\mathrm{CO}_{2}$ sensors located in buildings sampled each of the calibration gases. The $\mathrm{CO}_{2}$ concentrations reported on the computer screen of the building's data acquisition system or on the $\mathrm{CO}_{2}$ sensor display were recorded ${ }^{2}$. The data obtained were processed to obtain an offset error and slope or sensor gain error using a leastsquares linear regression of measured $\mathrm{CO}_{2}$ concentration verses "true" $\mathrm{CO}_{2}$ concentration. If a sensor agreed exactly with the "true" concentration, then the offset error would be 0 and the slope equal unity. However, an offset error of $50 \mathrm{ppm}$ would indicate that the sensor would read $50 \mathrm{ppm}$ high at a concentration of $0 \mathrm{ppm}$. A slope of 0.75 would indicate that slope of curve of reported concentration plotted versus true concentration is 0.75 . We employed these multipoint calibrations when the $\mathrm{CO}_{2}$ sensors had an inlet port and the sensor had a concentration display or the building operator was able and willing to program the data acquisition system so that data were provided with sufficient frequency (e.g., every several minutes) to make a multipoint calibration possible with calibration gas bags of a practical volume. This type of performance test was completed for 18 sensors from six buildings.

When a multi-point calibration was not possible, we performed a single-point calibration check of the building's $\mathrm{CO}_{2}$ sensors using a co-located and calibrated reference instrument. The protocol was very simple. A research grade $\mathrm{CO}_{2}$ instrument was calibrated, taken to the building, and placed so that it sampled at the same location as the building's $\mathrm{CO}_{2}$ sensor. Data from the reference instrument was logged over time. $\mathrm{CO}_{2}$ concentrations reported on the sensor's display or the building's data acquisition system's screen were recorded manually. The data were processed to obtain an absolute error, equal to the $\mathrm{CO}_{2}$ concentration reported by the building's data acquisition system minus the true $\mathrm{CO}_{2}$ concentration. We also calculated a percentage error equal to the absolute error divided by the true $\mathrm{CO}_{2}$ concentration, multiplied by $100 \%$. This type of sensor performance check was completed for 37 sensors located in seven buildings, including single point calibration checks in a few buildings where multi-point calibrations were completed. One limitation of the single point calibration data is that all of these data were obtained at low $\mathrm{CO}_{2}$ concentrations of 470 ppm or less.

\footnotetext{
${ }^{2}$ In three buildings, the $\mathrm{CO}_{2}$ concentrations on the $\mathrm{CO}_{2}$ sensor's display were used, but in all cases we confirmed that the building's data acquisition system reported the same $\mathrm{CO}_{2}$ concentration as the sensor display.
} 
The reference instrument used for the single point calibrations was the EGM-4 model from PP Systems, Amesbury, MA. The instrument has an automatic zero feature and is calibrated with a span gas. The rated accuracy is "better than $1 \%$ of span concentration but limited by the accuracy of the calibration gas mixture”. In our study, the span gas concentration was 2356 ppm and rated at $\pm 2 \%$ accuracy. We also performed a multipoint calibration check of this reference instrument during six field site visits. The offset errors indicated by these calibration checks ranged from -18 to $+17 \mathrm{ppm}$. The calibration slopes slope were 1.01 or 1.02 in five calibration checks and equaled 0.96 in the sixth calibration check $\left(\mathrm{R}^{2}\right.$ equaled 1.00 in all calibration checks). Additionally, at one time, the calibrated EGM-4 was intercompared with another research grade, but less accurate, $\mathrm{CO}_{2}$ instrument. In the four point intercomparison, the deviations ranged from -27 to $+33 \mathrm{ppm}$ with corresponding percentage errors of -1.9 to $+4.9 \%$. Finally, we used the calibrated EGM-4 analyzer to measure the $\mathrm{CO}_{2}$ concentrations in two cylinders of $\mathrm{CO}_{2}$ calibration gas that were not employed in the EGM's calibration. In these two measurements, the EGM reported a $\mathrm{CO}_{2}$ concentration approximately $30 \mathrm{ppm}$ less than indicated on the calibration gas cylinders. Altogether, these tests imply that the uncertainty in our reference $\mathrm{CO}_{2}$ measurements was about $\pm 30 \mathrm{ppm}$.

All of the sensors evaluated were non dispersive infrared sensors with a default measurement range of zero to $2000 \mathrm{ppm}$, although in some cases other ranges could be selected. The manfacturers' accuracy specifications ranged from $\pm 40 \mathrm{ppm} \pm 3 \%$ of reading to \pm 100 ppm over 5 years. Some sensors have a dual wavelength system detect and control for calibration drift, some used a single wavelength sensor and corrected for calibration drift with an algorithm assuming that the minimum measured concentration equals a reference value (e.g., 400 ppm). Most sensors sampled via diffusion, i.e., had no sample pump. The manufacturers' recommended calibration frequency ranged from every six months to every five years.

The sensor performance checks were all performed in commercial buildings located in California, selected without consideration of building age or type of $\mathrm{CO}_{2}$ sensor. The buildings were used for healthcare, education, software industry, judicial, and state office applications. There were six brands of $\mathrm{CO}_{2}$ sensors ${ }^{3}$ and multiple model types of some brands.

\section{RESULTS}

\section{Multi-point Calibration Checks}

Table 1 and Figure 1 provide results from the multi-point calibration checks of $\mathrm{CO}_{2}$ sensors. Offset errors ranged from -113 to +326 ppm. For 14 of 18 sensors, the offset error was less than $75 \mathrm{ppm}$. The slope of the curve of measured versus true $\mathrm{CO}_{2}$ concentration ranged from 0 to 1.35. For 8 of 18 sensors, the slope was within 0.05 of unity. Based on the offset error and slope, Table 1 provides predicted $\mathrm{CO}_{2}$ concentration measurement errors at true $\mathrm{CO}_{2}$ concentrations of 600 and $1000 \mathrm{ppm}$. At $600 \mathrm{ppm}$, predicted errors ranged from $-594 \mathrm{ppm}$ to +537 ppm. For 11 of 18 sensors, the predicted error at 600 ppm was less than $100 \mathrm{ppm}$. The

\footnotetext{
${ }^{3}$ Some manufacturers do not make theier own sensors, they market sensors from other manufacturers.
} 
accuracy of sensors of the same brand was highly variable. There was not sufficient data to draw conclusions about the trend in sensor accuracy with a sensor age.

Table 1. Results of multi-point calibration checks of $\mathrm{CO}_{2}$ sensors.

\begin{tabular}{|c|c|c|c|c|c|c|c|c|}
\hline $\begin{array}{l}\text { Build } \\
\text {-ing }\end{array}$ & Sensor Code & $\begin{array}{l}\text { Offset } \\
\text { Error } \\
\text { (ppm) }\end{array}$ & Slope & $\mathbf{R}^{2}$ & $\begin{array}{c}\text { Predicted } \\
\text { Error at } \\
600 \mathrm{ppm} \\
(\mathrm{ppm})\end{array}$ & $\begin{array}{l}\text { Predicted } \\
\text { Error at } \\
1000 \text { ppm } \\
(\mathrm{ppm})\end{array}$ & $\begin{array}{c}\text { Reported } \\
\text { Sensor Age } \\
\text { (years) }\end{array}$ & $\begin{array}{c}\text { Sensor } \\
\text { Manu- } \\
\text { facturer } \\
\text { Code }\end{array}$ \\
\hline 1 & Unit 1-1* & -55 & 0.89 & 0.99 & -119 & -161 & -- & 1 \\
\hline 1 & Unit 2-1* & -113 & 0.43 & 0.68 & -454 & -681 & -- & 2 \\
\hline 1 & Unit 2-2* & -77 & 0.32 & 0.76 & -488 & -762 & -- & 2 \\
\hline 1 & Unit 2-3* & 6 & 0.00 & 0.15 & -594 & -994 & -- & 1 \\
\hline 4 & 1015 & 45 & 1.03 & 1.00 & 62 & 73 & 1 & 4 \\
\hline 4 & 1016 & 49 & 1.00 & 1.00 & 49 & 50 & 1 & 4 \\
\hline 5 & Circle & 326 & 1.35 & 1.00 & 537 & 678 & 5 & 5 \\
\hline 5 & Triangle & -2 & 1.09 & 1.00 & 51 & 86 & 5 & 5 \\
\hline 5 & Square & -19 & 1.23 & 1.00 & 117 & 207 & 5 & 5 \\
\hline 6 & Courtroom 1 & 32 & 1.03 & 1.00 & 50 & 62 & 2 & 4 \\
\hline 6 & Courtroom 3 & 45 & 0.98 & 1.00 & 31 & 22 & 2 & 4 \\
\hline 6 & Courtroom 4 & -6 & 1.16 & 1.00 & 91 & 155 & 2 & 4 \\
\hline 6 & Courtroom 5 & 57 & 1.03 & 1.00 & 73 & 84 & 2 & 4 \\
\hline 7 & $\begin{array}{c}\text { Classroom } \\
110 \\
\end{array}$ & 81 & 1.50 & 1.00 & 381 & 581 & 1 & 6 \\
\hline 7 & $\begin{array}{c}\text { Classroom } \\
127\end{array}$ & 39 & 0.98 & 1.00 & 26 & 18 & 1 & 6 \\
\hline 8 & Library 232 & 21 & 1.00 & 1.00 & 24 & 26 & 1 & 6 \\
\hline 9 & AHU 2 & 18 & 1.04 & 1.00 & 42 & 58 & 1 & 6 \\
\hline 9 & AHU 1 & 56 & 0.94 & 1.00 & 20 & -5 & 1 & 6 \\
\hline
\end{tabular}

*sensor pump not working, calibration gas pushed through sensor

Note: $\mathrm{R}^{2}$ is the square of the Pearson correlation coefficient
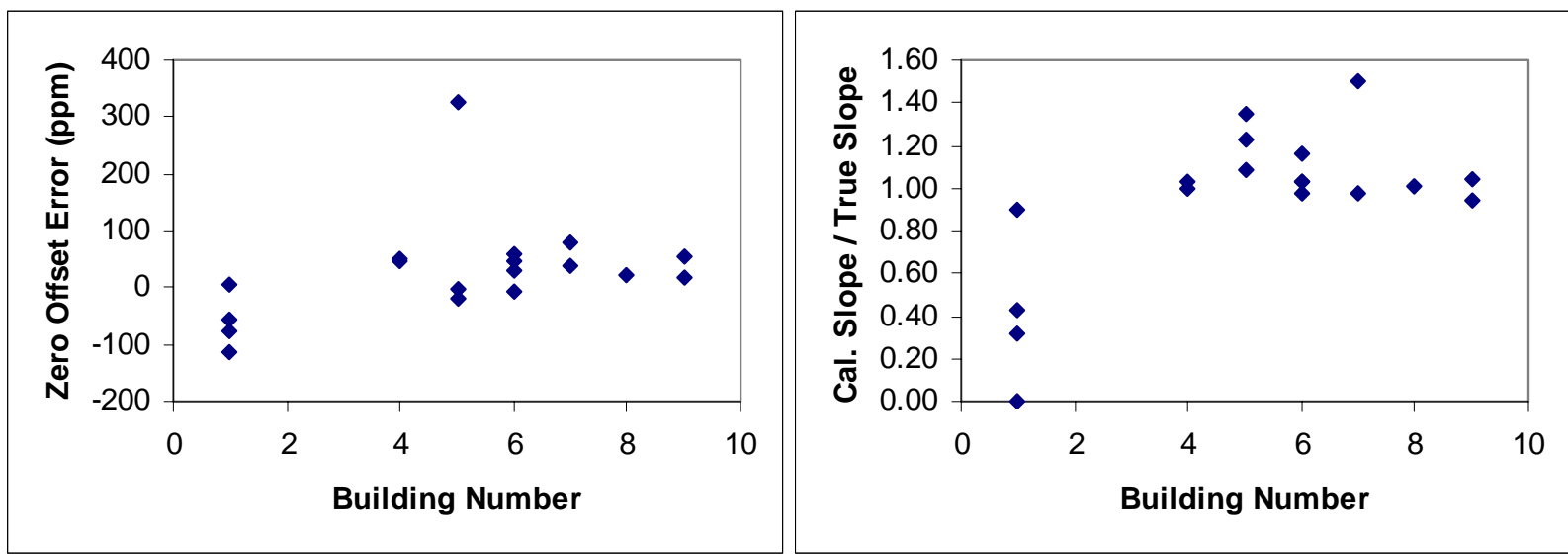

Figure 1. Zero offset errors and slopes from multipoint calibration checks of $\mathrm{CO}_{2}$ sensors.

\section{Single Point Calibration Checks}

Table 2 and Figure 2 provide the results of the single point calibration checks of $\mathrm{CO}_{2}$ sensors. Absolute errors ranged from -378 to +1013 ppm. The average and median of the absolute 
values of absolute error were 256 and $173 \mathrm{ppm}$, respectively. Percentage errors ranged from $100 \%$ to $+258 \%$. The average and median of the absolute values of percent error were $68 \%$ and $43 \%$, respectively. These single point calibration checks occurred with low $\mathrm{CO}_{2}$ concentrations, so percentage errors would likely be less at higher concentrations.

The errors were especially large in Building 2. Excluding the data from Building 2, the average and median of the absolute values of absolute error were $131 \mathrm{ppm}$ and $76 \mathrm{ppm}$, respectively. Excluding the data from Building 2, the average and median of the absolute values of percent error were $31 \%$ and $18 \%$, respectively.
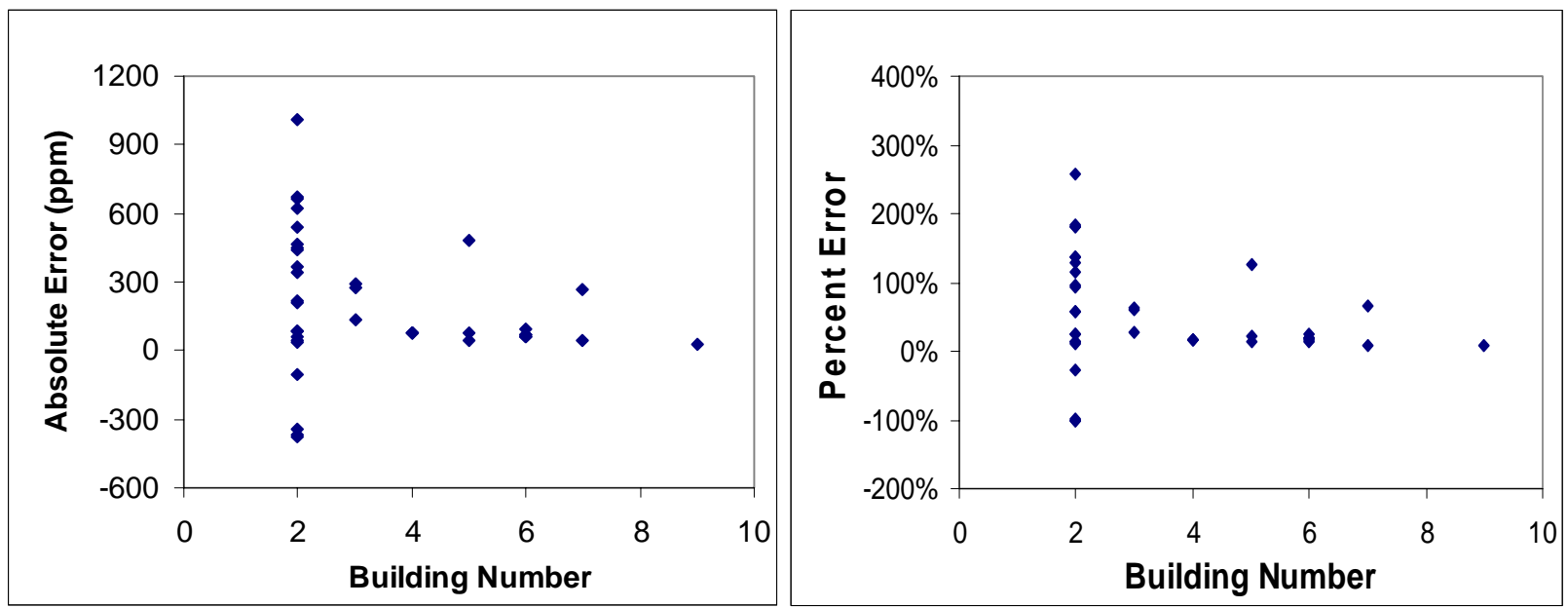

Figure 2. Absolute and percent errors from single point calibration checks of $\mathrm{CO}_{2}$ sensors.

\section{Comparison of multi-point and single point calibration checks}

Both multipoint and single point calibration checks were completed for twelve $\mathrm{CO}_{2}$ sensors. To evaluate the consistency of these two sensor assessment methods, we used the offset error and slope of each of the twelve multipoint calibration checks to predict the absolute error in the corresponding single point calibration check. The differences between the twelve predicted and actual measured single-point errors ranged from -35 to $+20 \mathrm{ppm}$ and the average of the absolute values of differences was $15 \mathrm{ppm}$. The modest magnitude of these differences is evidence of the validity of using the offset error and slope to characterize sensor accuracy. 
Table 2. Results of single-point calibration checks of $\mathrm{CO}_{2}$ sensors.

\begin{tabular}{|c|c|c|c|c|c|c|}
\hline $\begin{array}{l}\text { Build } \\
\text { - ing }\end{array}$ & Sensor Code & $\begin{array}{l}\text { “True” } \\
\text { Conc. } \\
\text { (ppm) }\end{array}$ & $\begin{array}{l}\text { Absolute Error } \\
(\mathbf{p p m})\end{array}$ & $\begin{array}{c}\% \\
\text { Error }\end{array}$ & $\begin{array}{c}\text { Reported Sensor } \\
\text { Age (years) }\end{array}$ & $\begin{array}{c}\text { Sensor } \\
\text { Manufacturer } \\
\text { Code }\end{array}$ \\
\hline 2 & $2 \mathrm{a}-1$ & 394 & 58 & $15 \%$ & 4 & 3 \\
\hline 2 & $2 a-2$ & 377 & 38 & $10 \%$ & 4 & 3 \\
\hline 2 & 3a-1 & 369 & 341 & $92 \%$ & 4 & 3 \\
\hline 2 & $3 a-2$ & 377 & 48 & $13 \%$ & 4 & 3 \\
\hline 2 & $4 a-1$ & 395 & 540 & $137 \%$ & 4 & 3 \\
\hline 2 & $4 a-2$ & 378 & -378 & $-100 \%$ & 4 & 3 \\
\hline 2 & $6 a-2$ & 376 & 215 & $57 \%$ & 4 & 3 \\
\hline 2 & 6a-2 repeat & 375 & 213 & $57 \%$ & 4 & 3 \\
\hline 2 & 7a-2 & 372 & -371 & $-100 \%$ & $<4$ & 4 \\
\hline 2 & $8 a-1$ & 360 & 662 & $184 \%$ & 4 & 3 \\
\hline 2 & $8 a-2$ & 350 & 89 & $25 \%$ & 4 & 3 \\
\hline 2 & 9a-1 & 368 & 668 & $182 \%$ & 4 & 3 \\
\hline 2 & 9a-2 & 393 & 1013 & $258 \%$ & 4 & 3 \\
\hline 2 & 10a-2 & 377 & 363 & $96 \%$ & 4 & 3 \\
\hline 2 & 11a-2 & 361 & -103 & $-29 \%$ & 4 & 3 \\
\hline 2 & 12a-1 & 396 & 452 & $114 \%$ & 4 & 3 \\
\hline 2 & 13a-1 & 342 & 621 & $182 \%$ & 4 & 3 \\
\hline 2 & 13a-2 & 340 & 437 & $129 \%$ & 4 & 3 \\
\hline 2 & 14a-1 & 342 & -342 & $-100 \%$ & 4 & 3 \\
\hline 2 & $14 a-2$ & 340 & 469 & $138 \%$ & 4 & 3 \\
\hline 2 & 15a-1 & 359 & 85 & $24 \%$ & 4 & 3 \\
\hline 3 & unit 1 & 462 & 292 & $63 \%$ & -- & 5 \\
\hline 3 & unit 2 & 463 & 276 & $60 \%$ & -- & 5 \\
\hline 3 & unit 3 & 487 & 133 & $27 \%$ & -- & 5 \\
\hline 4 & 1015 & 457 & 74 & $16 \%$ & 1 & 4 \\
\hline 4 & 1016 & 459 & 76 & $17 \%$ & 1 & 4 \\
\hline 4 & 1017 & 472 & 78 & $17 \%$ & 1 & 4 \\
\hline 5 & Circle & 378 & 482 & $127 \%$ & 5 & 5 \\
\hline 5 & Triangle & 376 & 48 & $13 \%$ & 5 & 5 \\
\hline 5 & Square & 358 & 76 & $21 \%$ & 5 & 5 \\
\hline 6 & Courtroom 1 & 381 & 69 & $18 \%$ & 2 & 4 \\
\hline 6 & Courtroom 2 & 364 & 92 & $25 \%$ & 2 & 4 \\
\hline 6 & Courtroom 3 & 380 & 71 & $19 \%$ & 2 & 4 \\
\hline 6 & Courtroom 4 & 391 & 59 & $15 \%$ & 2 & 4 \\
\hline 6 & Courtroom 5 & 423 & 63 & $15 \%$ & 2 & 4 \\
\hline 7 & Classroom 110 & 413 & 267 & $65 \%$ & 1 & 7 \\
\hline 7 & Classroom 127 & 466 & 43 & $9 \%$ & 1 & 7 \\
\hline 9 & AHU 1 & 350 & 29 & $8 \%$ & 1 & 7 \\
\hline
\end{tabular}

\section{DISCUSSION}

To place the results of this study in context, one must have an estimate of the required accuracy of $\mathrm{CO}_{2}$ sensors used in commercial buildings, e.g., for demand controlled ventilation. While 
most systems only measure the indoor $\mathrm{CO}_{2}$ concentration ${ }^{4}$, the difference between indoor and outdoor $\mathrm{CO}_{2}$ concentration is a better indicator of building ventilation rate and outdoor $\mathrm{CO}_{2}$ concentrations in urban areas vary significantly. One needs to be able to distinguish with reasonable, e.g., 20\%, accuracy the difference between peak indoor and outdoor $\mathrm{CO}_{2}$ concentrations found in commercial buildings. The most representative data set is that obtained from a survey of 100 office buildings by the U.S. Environmental Protection Agency (EPA). This EPA study measured and recorded five-minute-average $\mathrm{CO}_{2}$ concentrations at three indoor locations and one outdoor location. If one considers the maximum one-hour average differences between indoor and outdoor $\mathrm{CO}_{2}$ concentration ${ }^{5}$ from this EPA study, the minimum was 55 ppm, maximum was 777 ppm, average was 310 ppm, and median was 269 ppm. If one selects a 20\% accuracy in measuring the average peak indoor-outdoor $\mathrm{CO}_{2}$ concentration difference as a minimum requirement, then $62 \mathrm{ppm}$ (one fifth of $310 \mathrm{ppm}$ ) is a minimum expectation for $\mathrm{CO}_{2}$ measurement accuracy in offices. Based on our predicted error at $600 \mathrm{ppm}$ from the multipoint calibration checks, seven of $18 \mathrm{CO}_{2}$ sensors would not meet this expectation, and many fail by a very large margin.

Classroom $\mathrm{CO}_{2}$ concentrations tend to be higher than office $\mathrm{CO}_{2}$ concentrations, thus, one might accept larger $\mathrm{CO}_{2}$ measurement errors in classrooms. The most representative large data set is from a survey of 201 classrooms (two thirds were modular classrooms) in California (CARB 2004). The study report does not provide peak indoor-outdoor $\mathrm{CO}_{2}$ concentration differences, but it does report that in $43 \%$ of classrooms indoor $\mathrm{CO}_{2}$ exceeded $1000 \mathrm{ppm}$ and that a typical outdoor $\mathrm{CO}_{2}$ concentration was $425 \mathrm{ppm}$. Thus, we can estimate that in $43 \%$ of classrooms, peak indoor $\mathrm{CO}_{2}$ exceeded outdoor $\mathrm{CO}_{2}$ by 575 ppm. The school-day average indoor $\mathrm{CO}_{2}$ concentration was 1070 ppm (an estimated 645 ppm above that outdoors) but presumably this average is substantially impacted by very high $\mathrm{CO}_{2}$ levels, above $2000 \mathrm{pm}$, in a modest number of classrooms. Based on these data, one might select one fifth of a typical $600 \mathrm{ppm}$ indooroutdoor concentration difference, i.e., 120 ppm, as a minimum expectation for $\mathrm{CO}_{2}$ measurement accuracy in classrooms. Based on our predicted error at $1000 \mathrm{ppm}^{6}$ from the multipoint calibration checks, eight of $18 \mathrm{CO}_{2}$ sensors would not meet this expectation, and several fail by a large margin.

Due to the small sample size, a formal statistical analysis of the relationship between accuracy and sensor manufacturer, design features, and sensor age was not warranted. From inspection of the data, sensors from manufacturer 4 and 6 appeared to have generally smaller errors. We suspect, based on sensor specifications, that manufacturer 6 uses a sensor from manufacturer 4 . Based on an examination of plots, there was no clear relationship of accuracy with sensor age.

This study has important limitations that should be mentioned. Because of the small sample size, this study should be considered only a pilot study to provide an initial indication of the in-situ performance of $\mathrm{CO}_{2}$ sensors. To obtain more representative data on $\mathrm{CO}_{2}$ sensor accuracy, a

\footnotetext{
${ }^{4}$ Some sensors use the lowest concentration measured in a period of time to automatically reset the sensor's zero reading. This automatic zeroing process assumes that $\mathrm{CO}_{2}$ concentrations in the building are periodically as low as the outdoor $\mathrm{CO}_{2}$ concentration and that that outdoor concentration has a specific value, e.g., $400 \mathrm{ppm}$.

${ }^{5}$ Based on authors' analyses of the $\mathrm{CO}_{2}$ data from this study.

${ }^{6}$ We used the predicted error at $600 \mathrm{ppm}$ for offices, because peak office $\mathrm{CO}_{2}$ concentrations tend to be near 600 ppm. We used the predicted error at $1000 \mathrm{ppm}$ for classrooms, because peak classroom $\mathrm{CO}_{2}$ concentrations tend to be near $1000 \mathrm{ppm}$.
} 
substantially larger study from a probability sample of buildings is needed. Second, the scope of this study scope was very limited. The reasons for poor $\mathrm{CO}_{2}$ sensor accuracy were not investigated. For example, based on the data collected, we cannot determine whether the identified accuracy problems are the consequence of technical limitations of low cost $\mathrm{CO}_{2}$ sensors or due to failures of sensor users to maintain and calibrate sensors.

\section{CONCLUSION}

The study provides a strong indication that the accuracy of $\mathrm{CO}_{2}$ sensors used in commercial buildings is frequently less than is needed to measure peak indoor-outdoor $\mathrm{CO}_{2}$ concentration differences with less than a $20 \%$ error. Thus, despite the small size of this study, we can conclude that there is a need for more accurate $\mathrm{CO}_{2}$ sensors and/or better sensor maintenance or calibration procedures.

\section{ACKNOWLEDGMENTS}

This work was supported by the Assistant Secretary for Energy Efficiency and Renewable Energy, Building Technologies Program of the U.S. Department of Energy under contract DEAC02-05CH11231. The author thanks Terry Logee of DOE for program management and Phil Haves and Mike Apte for reviews of a draft of this paper.

\section{REFERENCES}

Apte MG (2006) A review of demand controlled ventilation. Proceedings of Healthy Buildings 2006, vol. IV, pp 371-376. Universidade do Porto, Portugal.

ASTM (1998) Standard guide for using indoor carbon dioxide concentrations to evaluate indoor air quality and ventilation. Designation D 6245-98. American Society for Testing and Materials. West Conshohocken, PA.

CARB (2004) Report to the California legislature - environmental health conditions in California's portable classrooms. California Air Resources Board and California Department of Health Services.

Emmerich SJ and Persily AK (2001) Stae of the art review of $\mathrm{CO}_{2}$ demand controlled ventilation technology and application. National Institute of Standards and Technology, NISTIR 6729, Gaithersburgh, MD.

Fisk, W.J. and de Almeida, A.T. (1998) "Sensor based demand controlled ventilation: a review", Energy and Buildings 29(1): 35-44.

Hoge, C.W., Reichler, M.R., Dominguez, E.A., Bremer, J.C., Mastro,T.D., Hendricks, K.A., Musher, D.M., Elliott, J.A., Facklam, R.R. and Breiman, R.F. (1994) “An Epidemic of 
pneumococcal disease in a overcrowded, inadequately ventilated jail”, The New England Journal of Medicine, 331: 643-648.

Seppanen, O.A., Fisk, W.J., and Mendell, M.J. (1999) Association of ventilation rates and $\mathrm{CO}_{2}$ concentrations with health and other human responses in commercial and institutional buildings. Indoor Air 9: 226-252.

Shaughnessy RJ, Haverinen-Shaughnessy U, Nevalainen A, D. Moschandreas D (2006) A preliminary study on the association between ventilation rates in classrooms and student performance. To be published in Indoor Air Journal, volume $16 .$.

Shendell DG, Prill R, Fisk WJ, Apte MG, Blake D, Faulkner D (2004) Associations between classroom $\mathrm{CO}_{2}$ concentrations and student attendance. Indoor Air 14(5): 333-341. 